\title{
Effect of Mg on microstructure and mechanical properties of Al-Mg alloys produced by high pressure torsion
}

\author{
Yang Liu ${ }^{\text {a }}$, Manping Liu ${ }^{\text {b,* }}$, Xuefei Chen ${ }^{\mathrm{c}, \mathrm{d}}$, Yang Cao ${ }^{\mathrm{c}}$, Hans J. Roven ${ }^{\mathrm{e}}$, Maxim Murashkin f,g, \\ Ruslan Z. Valiev ${ }^{\text {f,g }}$, Hao Zhou ${ }^{\text {c,* }}$ \\ a Department of Materials Science and Engineering, Northwestern University, Evanston, IL 60201, USA \\ b School of Materials Science E' Engineering, Jiangsu University, Zhenjiang 212013, China \\ c Nano and Heterogeneous Materials Center, School of Materials Science and Engineering, Nanjing University of Science and Technology, Nanjing 210094, China \\ d State Key Laboratory of Nonlinear Mechanics, Institute of Mechanics, Chinese Academy of Sciences, Beijing 100190, China \\ e Department of Materials Science and Engineering, Norwegian University of Science and Technology, Trondheim 7491, Norway \\ ${ }^{\mathrm{f}}$ Institute for Physics of Advanced Materials, Ufa State Aviation Technical University, Ufa 450008, Russia \\ ' Saint Petersburg State University, 7/9 Universitetskaya nab., Saint Petersburg 199034, Russia
}

\section{A R T I C L E I N F O}

\section{Article history:}

Received 27 August 2018

Received in revised form 14 September 2018

Accepted 20 September 2018

Available online $\mathrm{xxxx}$

\section{Keywords:}

Al-Mg alloys

High pressure torsion

Nanocrystalline materials

Transmission electron microscopy

\begin{abstract}
A B S T R A C T
Al-Mg alloys are a series of low cost and low density Al alloys, which show remarkable strengthening during deformation. In this work, study of commercial purity $\mathrm{Al}, \mathrm{Al}-0.5 \mathrm{Mg}$ and $\mathrm{Al}-4.1 \mathrm{Mg}$ alloys was carried out to investigate the effect of Mg on materials strengthening. Slight solid solution strengthening by $\mathrm{Mg}$ addition is found in the as-cast alloys. While further significant strengthening effect is achieved in the alloys produced by high pressure torsion. An extraordinarily high strength of $\sim 800 \mathrm{MPa}$ is achieved in the $\mathrm{Al}-4.1 \mathrm{Mg}$ alloy, as a result of deformation induced ultrafine grains, high density stacking faults and Mg segregation.
\end{abstract}

(C) 2018 Published by Elsevier Ltd on behalf of Acta Materialia Inc.
Environmental pollution and energy resource exhaustion pose major threats to the well-being of humanity. Thus, environmental protection and energy conservation are increasingly concerned in many industries. In recent years, aluminum alloys have been widely used on ships, vehicles and aircrafts due to its high specific strength, excellent corrosion resistance, good formability and decent machinability [1-4]. Increasing efforts have been devoted to improve mechanical performance of $\mathrm{Al}$ alloys for expanding their applications [5].

Strain hardening, grain boundary strengthening, solid solution strengthening and precipitation strengthening are the four major mechanisms for improving strength of Al alloys [6-10]. 7xxx and 5xxx series $\mathrm{Al}$ alloys are popular materials for both industrial applications and scientific research due to their outstanding mechanical properties. 7xxx series Al alloy can be processed to have a yield strength (YS) up to $0.7 \mathrm{GPa}$ by aging treatment [11]. The precipitation process in 7xxx series alloys follows the sequence of Solid solution $\rightarrow$ GP zones (GPZs) $\rightarrow$ Metastable $\eta^{\prime} \rightarrow$ Stable $\eta\left(\operatorname{MgZn}_{2}\right)$. The $\eta^{\prime}$ and $\eta$ phases, which are both hexagonal lattice structures co-existing in the peak aged sample [12]. The metastable $\eta$ ' phase is a semi-coherent phase within the Almatrix, and has generally a hexagonal structure with lattice parameters

\footnotetext{
* Corresponding authors.

E-mail addresses: manpingliu@ujs.edu.cn (M. Liu), hzhou0511@njust.edu.cn (H. Zhou).
}

of $\mathrm{a}=0.496 \mathrm{~nm}$ and $\mathrm{c}=1.402 \mathrm{~nm}[13]$. The stable $\eta$-phase, is usually in the size range of $1-50 \mathrm{~nm}$, has lattice parameters of $\mathrm{a}=0.515 \mathrm{~nm}$ and $\mathrm{c}$ $=0.86 \mathrm{~nm}$. These precipitates can impede dislocation slip effectively during deformation, thus strengthen the material [14]. Liddicoat et al. [7] reported a ultrahigh strength 7075 alloy produced by high pressure torsion (HPT), with a YS of 1 GPa. The ultrahigh strength of the material is attributed to the hierarchical nanostructure containing nano-grains, a high density of dislocations, solute clusters and intergranular solute structures. However, complex alloy systems inevitably make the materials costly, resource-dependent and difficult to recycle [15]. Nevertheless, the addition of heavy elements in Al alloys is against the concept of weight reduction.

In contrast, the $5 x x x$ series $\mathrm{Al}$ alloys have several advantages over $7 \mathrm{xxx}$ series Al alloys, including high ductility, low cost, low density, low alloying content, single phase structure (free of precipitates). In an attempt to improve the mechanical properties of $5 \mathrm{xxx}$ series $\mathrm{Al}$ alloys, Chang et al. [16] processed $5083 \mathrm{Al}$ alloy with equal-channel angular pressing (ECAP). The ECAPed 5083 Al alloy possessed a nanostructure and enhanced YS of $\sim 400 \mathrm{MPa}$. Note that both HPT and ECAP are popular severe plastic deformation (SPD) methods. The typical microstructural change made by SPD is grain size reduction down to ultrafine-grained regime $[10,17,18]$. Therefore, Hall-Petch type grain boundary strengthening effect is mostly considered when investigating the relationship between microstructures and mechanical properties 
$[19,20]$. In recent years, much attention has been shifted to elemental segregation during plastic deformation and the resulting effect on the microstructural evolution and mechanical properties of structural materials [21,22]. It has been noticed that slight increase of $\mathrm{Mg}$ content in $\mathrm{Al}-$ $\mathrm{Mg}$ alloys can effectively reduce the steady state grain size attained by SPD $[23,24]$. However, there is still lack of the detail about the underlying physics which relates to stacking fault energy (SFE) and the segregation of $\mathrm{Mg}$ in the alloys.

In this work, three Al-Mg alloys with different $\mathrm{Mg}$ contents were studied in order to investigate the effect of Mg addition on microstructural evolution and mechanical properties of the Al alloys processed by SPD. High resolution TEM was employed for detailed analysis on the micro/nanostructures. The result shows that as the $\mathrm{Mg}$ content increases, the steady state grain size decreases and the density of stacking faults increases. The segregation of $\mathrm{Mg}$ to boundaries suppressed dynamic recovery, resulting in a large fraction of non-equilibrium grain boundaries [21,25,26].

As-cast commercial purity Aluminum (CP-Al), Al-0.5Mg alloy and $\mathrm{Al}-4.1 \mathrm{Mg}$ alloy (wt\%) were selected as the model materials. Both $\mathrm{Al}-$ $0.5 \mathrm{Mg}$ and $\mathrm{Al}-4.1 \mathrm{Mg}$ alloys were firstly heat treated at $380{ }^{\circ} \mathrm{C}$ for $2 \mathrm{~h}$ (T4) to obtain a single phase solid solution. Then all the samples were cut into disks with an diameter of $20 \mathrm{~mm}$ and a thickness of $1 \mathrm{~mm}$. HPT processing of the disk samples was performed at room temperature under a pressure of $6 \mathrm{GPa}$. Each sample was HPTed to 10 revolutions at $1.5 \mathrm{rpm}$. HPT caused significant thickness reduction to the samples from $1.0 \mathrm{~mm}$ to $0.8 \mathrm{~mm}$. X-ray diffraction analysis was conducted on the HPTed samples, revealing single phase structures (the X-ray diffraction analysis results are provided in the Supplementary material). The dogbone shaped specimens with a gauge length of $1.8 \mathrm{~mm}$ and width of $1 \mathrm{~mm}$ were cut from the HPTed samples. The uniaxial tensile tests were performed with a LTM-20 kN testing machine with a strain rate of $9 \times 10^{-4} \mathrm{~s}^{-1}$, at ambient temperature. TEM samples were taken at specific locations on the disks, to ensure the microstructure of the sample has a close relation with the tensile test result. Ion milling was carried out on a cold stage $\left(-50{ }^{\circ} \mathrm{C}\right)$ with low beam energy $(<3 \mathrm{keV})$ to create electron transparent areas on the TEM samples [27]. Atomicresolution TEM was conducted with an aberration-corrected TEM (FEI Titan G2) operating at $300 \mathrm{kV}$.

Figs. 1a-c show the tensile test results of $\mathrm{CP}-\mathrm{Al}, \mathrm{Al}-0.5 \mathrm{Mg}$ and $\mathrm{Al}-$ $4.1 \mathrm{Mg}$ materials, respectively. It is clearly shown in the figures that HPTed samples have significantly improved strength but low ductility, comparing to as-cast samples. Table 1 lists the YS, ultimate tensile strength (UTS) and uniform elongation of the tested samples. CP-Al has a YS of $45 \mathrm{MPa}$. As the weight fraction of $\mathrm{Mg}$ is increased to $0.5 \%$ and $4.1 \%$, the YS is increased to $57 \mathrm{MPa}$ and $115 \mathrm{MPa}$, respectively. Thus, the solid solution strengthening effect is noticeable in the ascast Al-Mg alloys. After HPT processing to 10 revolutions, the YS and UTS of CP-Al were increased by $100 \mathrm{MPa}$ (from $45 \mathrm{MPa}$ to $145 \mathrm{MPa}$ ) and $125 \mathrm{MPa}$ (from $75 \mathrm{MPa}$ to $200 \mathrm{MPa}$ ), respectively. In contrast, the YS and UTS of Al-0.5Mg were increased by $333 \mathrm{MPa}$ (from $57 \mathrm{MPa}$ to $390 \mathrm{MPa}$ ) and $385 \mathrm{MPa}$ (from $105 \mathrm{MPa}$ to $490 \mathrm{MPa}$ ), respectively; the
Table 1

Mechanical properties of pure $\mathrm{Al}, \mathrm{Al}-0.5 \mathrm{Mg}$ and $\mathrm{Al}-4.1 \mathrm{Mg}$ alloys.

\begin{tabular}{lllll}
\hline & Alloys & Pure Al & Al-0.5Mg & Al-4.1Mg \\
\hline T4 & YS (MPa) & 45 & 57 & 115 \\
& UTS (MPa) & 75 & 105 & 255 \\
\multirow{3}{*}{ HPTed } & UE (\%) & 25 & 20 & 24 \\
& YS (MPa) & 145 & 390 & 690 \\
& UTS (MPa) & 200 & 490 & 800 \\
& UE (\%) & 8 & 6 & 2 \\
\hline
\end{tabular}

YS and UTS of Al-4.1Mg were increased by $575 \mathrm{MPa}$ (from $115 \mathrm{MPa}$ to $690 \mathrm{MPa}$ ) and $545 \mathrm{MPa}$ (from $255 \mathrm{MPa}$ to $800 \mathrm{MPa}$ ), respectively. This result reveals that $\mathrm{Mg}$ addition in Al can significantly enhance the SPD induced strengthening. It is also worth to mention that the HPTed Al$0.5 \mathrm{Mg}$ has $6 \%$ uniform elongation, which is decent for industrial applications.

In order to reveal the strengthening mechanism, detailed TEM analysis was conducted on the microstructures of the Al alloys. After HPT processing to 10 revolutions, the average grain sizes of the $\mathrm{CP}-\mathrm{Al}, \mathrm{Al}-$ $0.5 \mathrm{Mg}$ alloy and Al-4.1Mg alloy are $\sim 393 \mathrm{~nm}, \sim 285 \mathrm{~nm}$ and $\sim 91 \mathrm{~nm}$, respectively, consistent with literatures [28-30]. As shown in Fig. 2a and $\mathrm{b}$, nearly all the grains have smooth grain boundaries (GBs), and grain interior is free of defect, in the HPT processed CP-Al. It is well-known that full dislocations are the major carriers of plastic strain in $\mathrm{CP}-\mathrm{Al}$ [31]. Full dislocations are likely to cross-slip, which facilitates dynamic recovery [26,32]. Thus, this result leads to a reasonable conclusion that strain induced dynamic recovery and dynamic recrystallization in $\mathrm{CP}$ $\mathrm{Al}$ have been vigorous before the end of HPT processing [33].

Fig. 2c shows grains of HPTed Al-0.5Mg alloy. By comparing the grain size distribution charts inserted in Figs. $2 \mathrm{a}$ and $\mathrm{c}$, it can be noticed that the range of grain size distribution is reduced from $175-775 \mathrm{~nm}$ for HPTed CP-Al to $100-475 \mathrm{~nm}$ for HPTed Al-0.5Mg alloy. The peak of the grain size distribution is shifted from $375 \mathrm{~nm}$ to $225 \mathrm{~nm}$ as the $\mathrm{Mg}$ content is increased to $0.5 \mathrm{wt} \%$. While the steady state grain size of the HPTed Al-0.5Mg alloy is much smaller than that of the HPTed CP$\mathrm{Al}$, most of the grains have smooth boundaries. These results indicate that addition of a small amount of $\mathrm{Mg}$ is very helpful for grain refinement, but does not significantly suppress dynamic recrystallization at such a high strain level. Fig. $2 \mathrm{~d}$ shows a stacking fault (SF) at the interior of a grain. This indicates that the addition of $\mathrm{Mg}$ and the small grain size have led to the activation of SFs. For the HPTed Al-4.1Mg alloy, the GBs are mostly ill-defined as shown in Fig. 2e. Thus, the majority of the subGBs formed during HPT are non-equilibrium boundaries [34], which are a result of dislocation accumulation and delayed dynamic recovery. As shown by the grain size distribution chart inserted in Fig. 2e, the steady state grain size of the HPTed Al-4.1Mg alloy are within the range of $25-225 \mathrm{~nm}$ and the peak grain size is $\sim 125 \mathrm{~nm}$. Fig. $2 \mathrm{f}$ shows a high density of SFs at the interior of a grain, indicating an increased defect content at the grain interior of the HPTed $\mathrm{Al}-4.1 \mathrm{Mg}$ alloy comparing to HPTed CP-Al and Al-0.5Mg alloy. The ill-defined GBs, the existence of SFs and the small grain size close to the nanocrystalline regime
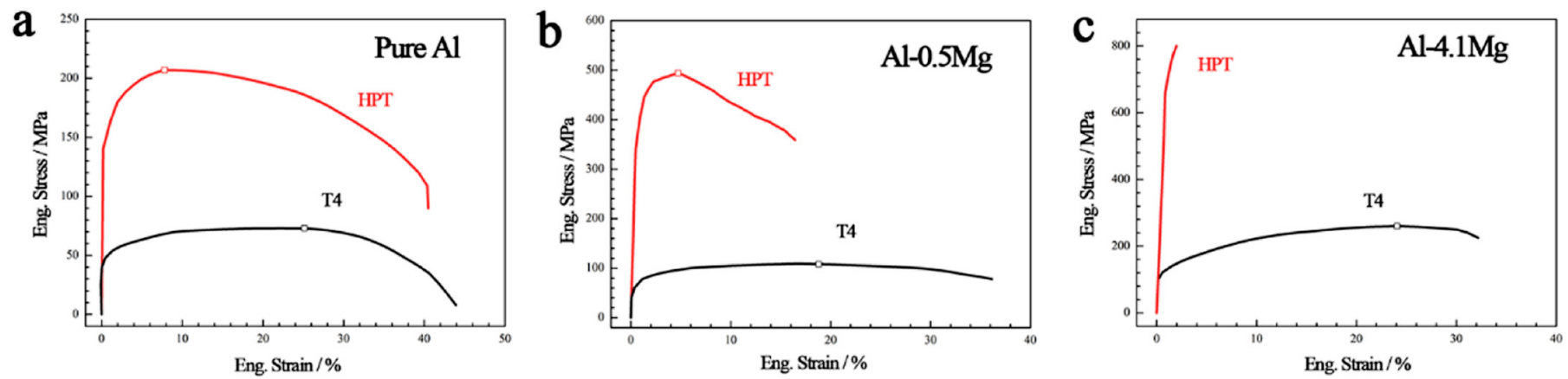

Fig. 1. Tensile stress-strain curves of the T4 and HPTed samples: (a) CP-Al, (b) Al-0.5Mg alloy, and (c) Al-4.1Mg alloy. 


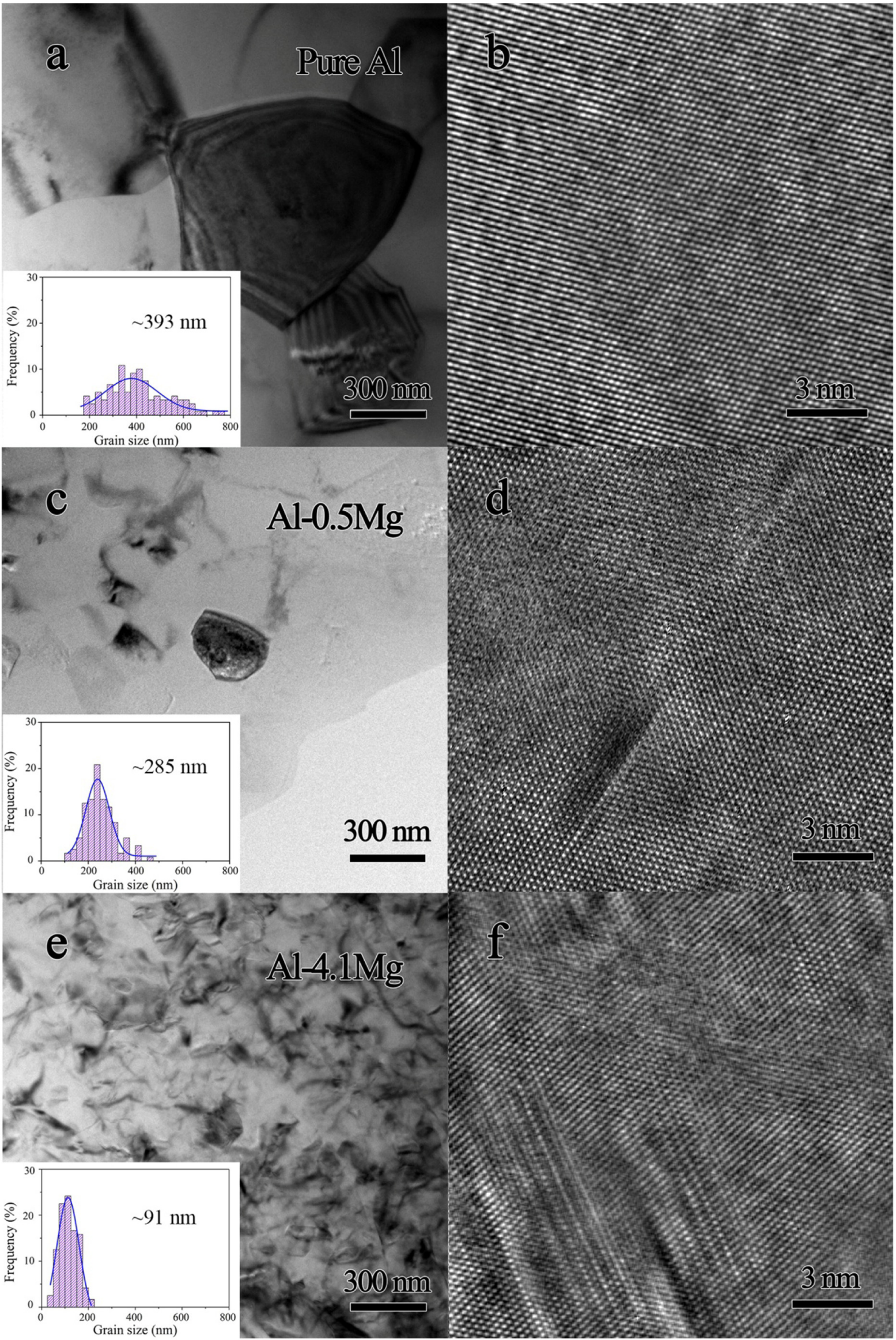

Fig. 2. TEM images of the samples processed by HPT: (a) and (b) CP-Al, (c) and (d) Al-0.5Mg alloy, and (e) and (f) Al-4.1Mg alloy; the insets are grain size distribution charts. 


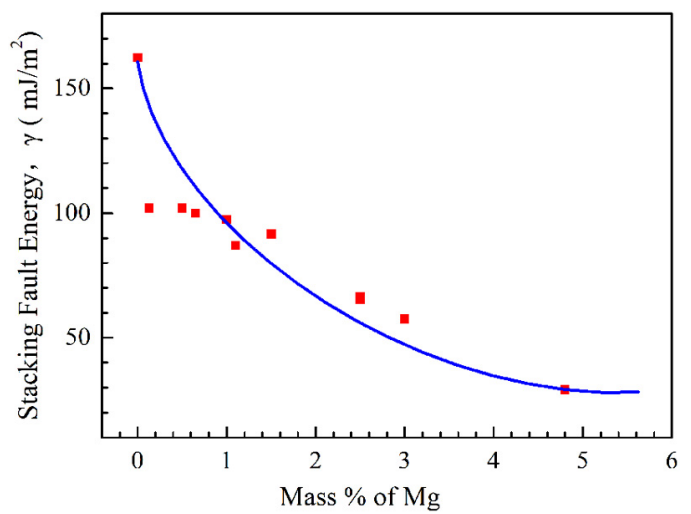

Fig. 3. Effect of Mg on stacking fault energy in aluminum alloys [39,40].

indicating that the SFs are formed by partial dislocation emission from GBs and triple junctions [26,35]. SFs in the dissociated form do not cross-slip, thus they may delay dynamic recovery. However, partial dislocation emission process is important to accommodate GB sliding and grain rotation, which may also facilitate dynamic recovery [36] and dynamic recrystallization [37] when the grain size is sufficiently small [26]. Since many of the GBs are still ill-defined, it is anticipated that dynamic recovery and dynamic recrystallization in the $\mathrm{Al}-4.1 \mathrm{Mg}$ alloy is much less pronounced than that in $\mathrm{CP}-\mathrm{Al}$ and $\mathrm{Al}-0.5 \mathrm{Mg}$ alloy. By comparing the steady state microstructures demonstrated in Fig. 2, it can be found that as the Mg content increases in Al-Mg alloys, the steady state grain size decreases, dynamic recovery and dynamic recrystallization are suppressed to a certain extent, and the SF activities become more pronounced $[10,38]$.

The shear strain imposed by HPT to the three model materials are the same, but the density of SFs increases with increasing Mg content. It is clear that $\mathrm{Mg}$ content has a significant effect on the SFE of the material. Fig. 3 shows a curve fitted to experimental data of the SFEs provided by literatures $[39,40]$. The SFE of CP-Al is very high $\left(>150 \mathrm{~mJ} \cdot \mathrm{m}^{-2}\right)$. Thus, it is difficult to form SFs in CP-Al, even under the ultrahigh strain imposed by HPT [26]. According to Fig. 3, SFE exhibits a drastic reduction with increasing $\mathrm{Mg}$ content. The SFEs of $\mathrm{Al}-$ $0.5 \mathrm{Mg}$ and $\mathrm{Al}-4.1 \mathrm{Mg}$ alloys are $\sim 120 \mathrm{~mJ} \cdot \mathrm{m}^{-2}$ and $\sim 40 \mathrm{~mJ} \cdot \mathrm{m}^{-2}$, respectively. The significantly decreased SFE led to different microstructures in the HPTed CP-Al, Al-0.5Mg alloy and Al-4.1Mg alloy.

Fig. 4 shows typical results of HAADF-STEM analysis and energydispersive X-ray spectroscopy (EDX) analysis of the HPTed Al-0.5Mg alloy and $\mathrm{Al}-4.1 \mathrm{Mg}$ alloy. A green straight line $\mathrm{AB}$ marks the EDX scanning path across two points on the GB as shown in Fig. 4a. Fig. 4b shows the corresponding EDX line scanning result. Although the total $\mathrm{Mg}$ content is only $0.5 \%$ in the alloy, segregation of $\mathrm{Mg}$ atoms at the GB is still evident. Similar phenomenon of Mg segregation at GBs is expectably found in HPTed Al-4.1Mg alloy, as demonstrated in Fig. 4c and d. Interestingly, as revealed by Fig. 4d, Mg segregation was not clearly detected at the intersection point close to the B end. Thus, the segregation of $\mathrm{Mg}$ is not uniform along GBs. According to literatures, during SPD processing both dislocations and vacancies continuously form and constantly flow towards GBs. Both dislocation slip and flux of vacancies are capable of dragging Mg atoms towards GBs. However, there are evidences showing that $\mathrm{Mg}$ atoms in $\mathrm{Al}$ matrix are much more likely to flow with vacancies than dislocations $[41,42]$. Moreover, the solute
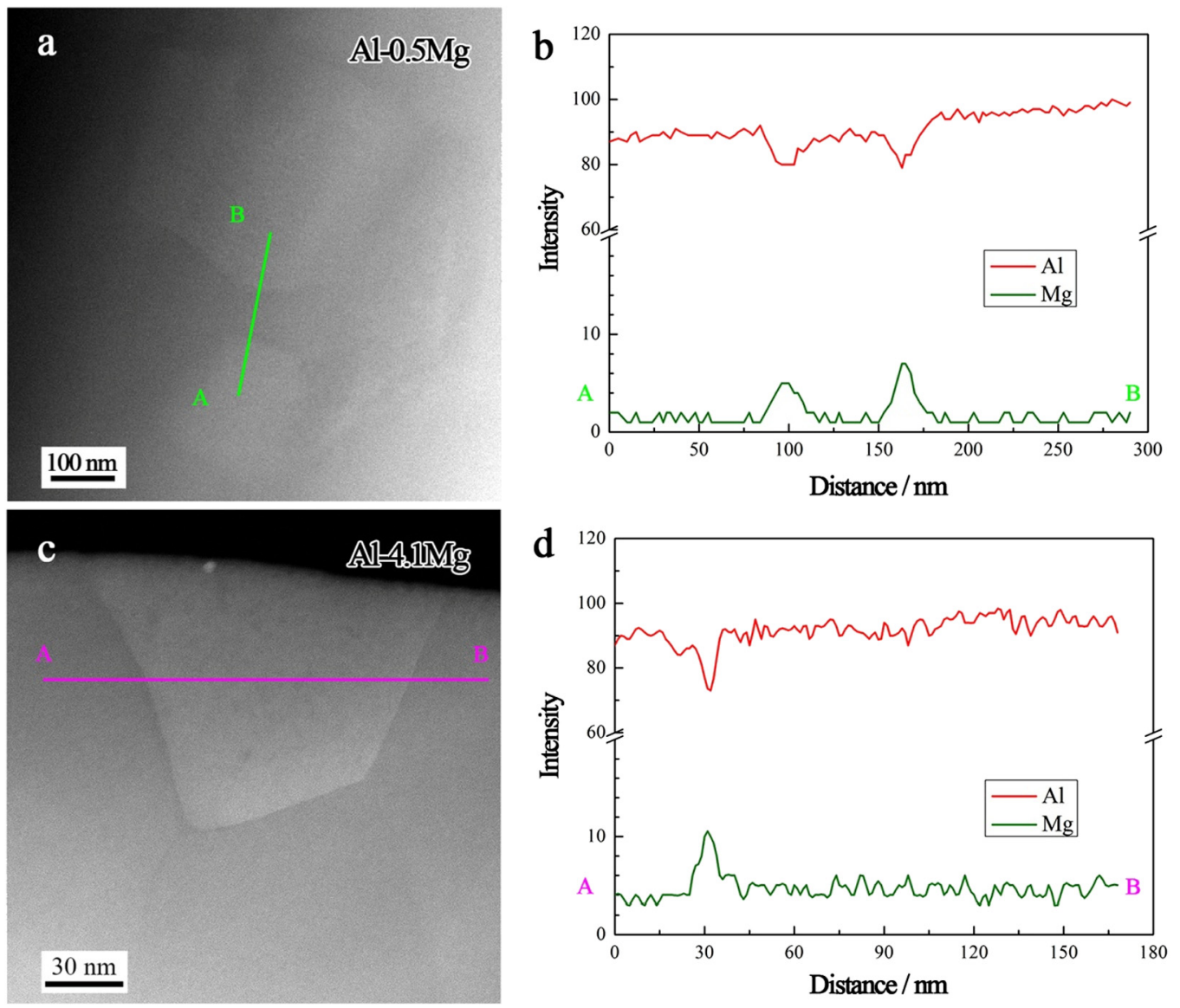

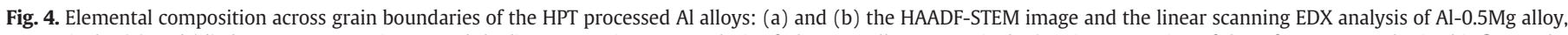

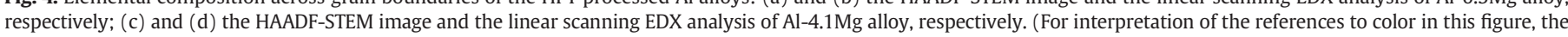
reader is referred to the web version of this article.) 
drag effect by both vacancies flux and dislocation slip are inhomogeneous attributed to local stress variation [43], thus resulting in local composition fluctuations along GBs as revealed in Fig. 4d and another literature [44].

The ultrahigh UTS of $\sim 800 \mathrm{MPa}$ achieved in the Al-4.1Mg alloy is reaching the record-breaking upper limit of $980 \mathrm{MPa}$ [7]. However, in the current case, the ultrahigh strength of the Al-4.1Mg alloy has been achieved without nanostructural hierarchy. Hall-Petch type GB strengthening and solid solution strengthening are the two major contributing effects. The lowered SFE led to significantly reduced grain size to $\sim 100 \mathrm{~nm}$ and a large amount of non-equilibrium sub-GBs. The strong segregation at the sub-GBs effectively delayed the dynamic recovery process and increased dislocation storage capacity by exerting strong pinning effect to the boundaries [21,45-47] and dislocations [22]. However, Mg segregation to GBs dilutes the solid solution within the grains [41,42], thus reducing the sold solution strengthening effect [48]. Nevertheless, the lowered SFE does lead to increased defect density at the grain interior (further increase of the dislocation storage capacity [49]) as shown in Fig. 2f, granting the materials with additional strain hardening effect. However, the defect density in the HPTed Al$4.1 \mathrm{Mg}$ alloy is not comparable to these representative materials with extremely high densities of defects [7,50]. Therefore, it is concluded that the addition of Mg can dramatically amplify the Hall-Petch type GB strengthening and grant additional strain hardening effect, at the small expense of solid solution strengthening. This discovery has pointed out a new route for processing single-phase Al alloys with outstanding mechanical properties.

Single phase $\mathrm{Al}-0.5 \mathrm{Mg}$ and $\mathrm{Al}-4.1 \mathrm{Mg}$ alloys have been processed by HPT to high strength of $490 \mathrm{MPa}$ and $800 \mathrm{MPa}$, respectively. In comparison to $\mathrm{CP}-\mathrm{Al}$, the overall strengthening effect of SPD is significantly amplified in the alloys, owing to the addition of $\mathrm{Mg}$. The addition of $\mathrm{Mg}$ is beneficial for strengthening $\mathrm{Al}-\mathrm{Mg}$ alloys for two major reasons: (1) $\mathrm{Mg}$ addition is very effective in lowering the SFEs of the Al-Mg alloys, thus the steady state grain size is reduced, and the dislocation density and the dislocation storage capacity are increased; (2) Mg atoms easily segregate to GBs under plastic deformation, as a result the mobility of GBs is reduced and defect densities at GBs are increased.

Supplementary data to this article can be found online at https://doi. org/10.1016/j.scriptamat.2018.09.033.

\section{Acknowledgments}

This research was funded by the National Key R\&D Program of China (Grant number 2017YFA0204403), the National Natural Science Foundation of China (Grant numbers U1710124, 51601003 and 51601094), and the financial support from Saint Petersburg State University in the framework of Call 3 project (Grant number 26130576). The authors wish to express their appreciation to the Jiangsu Key Laboratory of Advanced Micro\&Nano Materials and Technology. TEM experiments were performed at the Materials Characterization and Research Center of Nanjing University of Science and Technology.

\section{References}

[1] C.M. Cepeda-Jiménez, J.M. García-Infanta, M. Pozuelo, O.A. Ruano, F. Carreño, Scr. Mater. 61 (2009) 407-410.

[2] R. Jayaganthan, H.-G. Brokmeier, B. Schwebke, S.K. Panigrahi, J. Alloys Compd. 496 (2010) 183-188

[3] X.C. Sha, X.F. Chen, H.Y. Ning, L.R. Xiao, D.D. Yin, L. Mao, J. Zheng, H. Zhou, Materials 11 (2018) 1151.
[4] T. Dursun, C. Soutis, Mater. Des. 56 (2014) 862-871.

[5] S. Fu, H.Q. Liu, N. Qi, B. Wang, Y. Jiang, Z.Q. Chen, T. Hu, D.Q. Yi, Scr. Mater. 150 (2018) 13-17

[6] K. Wang, H.Y. Jiang, Y.W. Jia, H. Zhou, Q.D. Wang, B. Ye, W.J. Ding, Acta Mater. 103 (2016) 252-263.

[7] P.V. Liddicoat, X.Z. Liao, Y.H. Zhao, Y.T. Zhu, M.Y. Murashkin, E.J. Lavernia, R.Z. Valiev, S.P. Ringer, Nat. Commun. 1 (2010) 63.

[8] Y. Buranova, V. Kulitskiy, M. Peterlechner, A. Mogucheva, R. Kaibyshev, S.V. Divinski, G. Wilde, Acta Mater. 124 (2017) 210-224

[9] H.L. Jia, R. Bjørge, K. Marthinsen, Y.J. Li, J. Alloys Compd. 697 (2017) 239-248.

[10] Y. Cao, S. Ni, X.Z. Liao, M. Song, Y.T. Zhu, Mater. Sci. Eng. R 133 (2018) 1-59.

[11] A. Esmaeili, M.H. Shaeri, M.T. Noghani, A. Razaghian, J. Alloys Compd. 757 (2018) 324-332.

[12] G. Sha, A. Cerezo, Acta Mater. 52 (2004) 4503-4516.

[13] R. Ghiaasiaan, B.S. Amirkhiz, S. Shankar, Mater. Sci. Eng. A 698 (2017) 206-217.

[14] L.K. Berg, J. Gjønnes, V. Hansen, X.Z. Li, M.K. Wedel, G. Waterloo, D. Schryvers, L.R. Wallenberg, Acta Mater. 49 (2001) 3443-3451

[15] X.Y. Li, K. Lu, Nat. Mater. 16 (2017) 700-701.

[16] S.-Y. Chang, B.-D. Ahn, S.-K. Hong, S. Kamado, Y. Kojima, D.H. Shin, J. Alloys Compd. 386 (2005) 197-201.

[17] K. Edalati, S. Toh, H. Iwaoka, M. Watanabe, Z. Horita, D. Kashioka, K. Kishida, H. Inui, Scr. Mater. 67 (2012) 814-817.

[18] R.Z. Valiev, T.G. Langdon, Prog. Mater. Sci. 51 (2006) 881-981.

[19] N. Hansen, Scr. Mater. 51 (2004) 801-806.

[20] T.L. Huang, L.F. Shuai, A. Wakeel, G.L. Wu, N. Hansen, X.X. Huang, Acta Mater. 156 (2018) 369-378.

[21] Y.J. Lin, H.M. Wen, Y. Li, B. Wen, W. Liu, E.J. Lavernia, Acta Mater. 82 (2015) 304-315.

[22] M. Kuzmina, M. Herbig, D. Ponge, S. Sandlöbes, D. Raabe, Science 359 (2015) 1080-1083.

[23] M.P. Liu, T.H. Jiang, X.F. Xie, Q. Liu, X.F. Li, H.J. Roven, Trans. Nonferrous Metals Soc. China 24 (2014) 3848-3857.

[24] R. Takai, S. Kimura, R. Kashiuchi, H. Kotaki, M. Yoshida, Mater. Sci. Eng. A 667 (2016) 417-425.

[25] J.Y. Huang, Y.T. Zhu, H. Jiang, T.C. Lowe, Acta Mater. 49 (2001) 1497-1505.

[26] Y.T. Zhu, X.Z. Liao, X.L. Wu, Prog. Mater. Sci. 57 (2012) 1-62.

[27] H. Zhou, G.M. Cheng, X.L. Ma, W.Z. Xu, S.N. Mathaudhu, Q.D. Wang, Y.T. Zhu, Acta Mater. 95 (2015) 20-29.

[28] Y. Ito, K. Edalati, Z. Horita, Mater. Sci. Eng. A 679 (2017) 428-434.

[29] K. Tugcu, G. Sha, X.Z. Liao, P. Trimby, J.H. Xia, M.Y. Murashkin, Y. Xie, R.Z. Valiev, S.P. Ringer, Mater. Sci. Eng. A 552 (2012) 415-418.

[30] A.A. Mazilkin, B.B. Straumal, E. Rabkin, B. Baretzky, S. Enders, S.G. Protasova, O.A. Kogtenkova, R.Z. Valiev, Acta Mater. 54 (2006) 3933-3939.

[31] Y.L. Wei, A. Godfrey, W. Liu, Q. Liu, X. Huang, N. Hansen, G. Winther, Scr. Mater. 65 (2011) 355-358.

[32] U.F. Kocks, H. Mecking, Prog. Mater. Sci. 48 (2003) 171-273.

[33] L. Balogh, T. Ungár, Y.H. Zhao, Y.T. Zhu, Z. Horita, C. Xu, T.G. Langdon, Acta Mater. 56 (2008) 809-820.

[34] X.L. Wu, Y.T. Zhu, Appl. Phys. Lett. 89 (2006), 031922.

[35] Mahajan, Scr. Mater. 68 (2013) 95-99.

[36] P. Kumar, K. Kawasaki, T.G. Langdon, J. Mater. Sci. 51 (2016) 7-18.

[37] L.H. Wang, J. Teng, P. Liu, A. Hirata, E. Ma, Z. Zhang, M.W. Chen, X.D. Han, Nat. Commun. 5 (2014) 4402

[38] L. Balogh, T. Ungár, Y.H. Zhao, Y.T. Zhu, Z. Horita, C. Xu, T.G. Langdon, Acta Mater. 56 (2008) 809-820.

[39] M. Muzyk, Z. Pakiela, K.J. Kurzydlowski, Scr. Mater. 64 (2011) 916-918.

[40] T. Morishige, T. Hirata, T. Uesugi, Y. Takigawa, M. Tsujikawa, K. Higashi, Scr. Mater. 64 (2011) 355-358.

[41] X. Sauvage, N. Enikeev, R. Valiev, Y. Nasedkina, M. Murashkin, Acta Mater. 72 (2014) 125-136.

[42] C.R.S. Beatrice, W. Garlipp, M. Cilense, A.T. Adorno, Scr. Metall. Mater. 32 (1995) 23-26.

[43] Y. Cao, Y.B. Wang, R.B. Figueiredo, L. Chang, X.Z. Liao, M. Kawasaki, W.L. Zheng, S.P. Ringer, T.G. Langdon, Y.T. Zhu, Acta Mater. 59 (2011) 3903-3914.

[44] R.Z. Valiev, N.A. Enikeev, M.Yu. Murashkin, V.U. Kazykhanov, X. Sauvage, Scr. Mater. 63 (2010) 949-952.

[45] J.F. Nie, Y.M. Zhu, J.Z. Liu, X.Y. Fang, Science 340 (2013) 957-960.

[46] L.H. Wang, X.D. Han, P. Liu, Y.H. Yue, Z. Zhang, E. Ma, Phys. Rev. Lett. 105 (2010) 135501

[47] G. Wu, K.-C. Chan, L.L. Zhu, L.G. Sun, J. Lu, Nature 545 (2017) 80-83.

[48] G.P.M. Leyson, L.G. Hector Jr., W.A. Curtin, Acta Mater. 60 (2012) 3873-3884.

[49] Z.W. Wang, Y.B. Wang, X.Z. Liao, Y.H. Zhao, E.J. Lavernia, Y.T. Zhu, Z. Horita, T.G. Langdon, Scr. Mater. 60 (2009) 52-55.

[50] B.B. He, B. Hu, H.W. Yen, G.J. Cheng, Z.K. Wang, H.W. Luo, M.X. Huang, Science 357 (2017) 1029-1032. 